Inger Hjørdis Bleskestad, ph.d. Markers of disturbed mineral metabolism in chronic kidney disease - with emphasis on kidney transplant patients. Utgår fra Klinisk institutt 1. Disputas 22.1. 2015.

Bedømmelseskomité: Bjørn Odvar Eriksen, Universitetet i Tromsø, Cecilia Margareta Montgomery Øien, Norges teknisknaturvitenskapelige universitet, og Håvard Søiland, Universitetet i Bergen.

Veileder: Lasse Gunnar Gøransson.

Pirjo-Riitta Salminen, ph.d. Myocardial protection and antiapoptotic intervention at reperfusion. Experimental studies in translational porcine models of myocardial ischemia and reperfusion. Utgår fra Klinisk institutt 2. Disputas 23.1. 2015. Bedømmelseskomité: Gary F. Baxter, Cardiff University, Storbritannia, Kristian Bartnes, Universitetet i Troms $\varnothing$ - Norges arktiske universitet, Eva Gerdts, Universitetet i Bergen. Veileder: Ketil Grong.

Alessandro De Bortoli, ph.d. Improving the procedural safety and efficacy of radiofrequency catheter ablation for atrial fibrillation. Utgår fra Klinisk institutt 2. Disputas 30.1. 2015.

Bedømmelseskomité: Günter Breithardt, Westfälischen Wilhelms-Universität Münster, Tyskland, Pekka Raatikainen, University of Eastern Finland, og Ketil Grong, Universitetet i Bergen. Veileder: Jian Chen.

Ingrid Kristin Torsvik, ph.d. $B$ vitamin and iron status during infancy. Utgår fra Klinisk institutt 2. Disputas 30.1. 2015.

Bedømmelseskomité: Olle Hernell, Universitetet i Umeå, Sverige, Claus Klingenberg, Universitetet i Troms $\emptyset$ - Norges arktiske universitet, og Bjørn Tore Gjertsen, Universitetet i Bergen. Veileder: Anne Lise Bjørke Monsen.

\section{- NTNU}

Det skapende universitet

http://www.ntnu.no/kalender\#tag=disputaserdmf

Bernhard Weidle, ph.d. Children and adolescents with obsessivecompulsive disorder: comorbidity and quality of life. Utgår fra Regionalt kunnskapssenter for barn og unge. Disputas 9.1. 2015. Bedømmelseskomité: Else De Haan, University of Amsterdam, Nederland, Andreas Warnke, Würzburg Klinik für Kinderpsychiatrie, Tyskland, og May Britt Drugli, Regionalt kunnskapssenter for barn og unge, Midt-Norge.

Veiledere: Thomas Jozefiak og Tord Ivarsson.
Lindy Jarosch-von Schweder, ph.d. Use of electroconvulsive therapy in psychiatry. Utgår fra Institutt for nevromedisin. Disputas 22.1. 2015.

Bedømmelseskomité: Axel Nordenskjöld, Örebro Universitet, Sverige, Turid Birgitte Boye, Universitetet i Oslo, og Egil Jonsbu, Norges teknisk-naturvitenskapelige universitet. Veiledere: Olav M. Linaker, Stian Lydersen, Per Bergsholm og Kari Ann Leiknes.

\section{Universitetet i Troms $\emptyset$ - Norges arktiske universitet http://uit.no/tavla/arr?uit_arr_kat=10,13}

Egil Støre Blix, ph.d. Advanced flow cytometry to study signaling pathways and predict outcome in B cell malignancies. Utgår fra Institutt for medisinsk biologi. Disputas 16.1. 2015.

Bedømmelseskomité: Michael Kneba, University Hospital Schleswig-Holstein, Campus Kiel, Tyskland, Bjørn Tore Gjertsen, Universitetet i Bergen, og Elin Synnøve Mortensen, Universitetet i Troms $\varnothing$ - Norges arktiske universitet.

Veiledere: Anne Husebekk, Arne Kolstad og June H. Myklebust.

\section{MELDTE DØDSFALL}

Arne Rugtveit 25.9. 1922-25.9. 2014

Arne Serck-Hanssen 28.2. 1925-27.11. 2014

Ingvald Andersson 2.11.1939-26.11. 2014 